atoms of cholesterol (fifteen from $\mathrm{CH}_{3}$, twelve from $\mathrm{CO}_{2} \mathrm{H}$ ). An amicable division of the field between the American and British groups has now led to an elucidation of the sources of all the individual carbon atoms in cholesterol (that is, whether from $\mathrm{CH}_{3}$ or $\mathrm{CO}_{2} \mathrm{H}$ ). This result, taken in conjunction with a much earlier hypothesis of Robinson that the acyclic triterpene squalene folds, with loss of three carbon atoms, into cholesterol, has permitted the elucidation of the major stages in the biosynthesis. A further great contribution has recently been made by Dr. K. Folkers and his group at Merck and Co., who have shown that the biochemical origin of the isopene unit is mevalonic acid $\left(\mathrm{HOCH}_{2} \mathrm{CH}_{2} \mathrm{C}(\mathrm{OH})\left(\mathrm{CH}_{3}\right) \mathrm{CH}_{2} \mathrm{CO}_{2} \mathrm{H}\right)$, which loses its carboxyl group in the process of incorporation. The overall process seems to be : acetic acid $\rightarrow X \rightarrow$ mevalonic acid $\rightarrow Y \rightarrow$ squalene $\rightarrow$ lanosterol (a $4: 4:$ 14-trimethyl steroid) $\rightarrow$ a $4: 4$-dimethyl steroid $\rightarrow$ zymosterol (a $\mathrm{C}_{27}$-steroid with $8: 14$ - and 24-double bonds) $\rightarrow$ desmosterol (5- and 24-double bonds) $\rightarrow$ cholesterol (5-double bond). The natures of some of the intermediates, notably $X$ and $Y$, and the exact mechanisms of some of the processes are still not at all clear.

The general impression left by the symposium was of rapid advance and a new air of certainty replacing somewhat misty speculations. However, it is clear that a pencil and paper are still very useful tools to produce useful and fruitful suggestions, if not proofs. Little time was left for discussion, and Sir Robert Robinson regretfully closed the symposium after thanking the speakers.
A. J. Birch

\title{
CONSTITUTION AND CARE OF THE INFANT ANIMAL
}

$\mathrm{S}^{\mathrm{B}}$ ECTIONS I (Physiology and Biochemistry) and M (Agriculture) of the British Association held a joint session during the recent meeting at Dublin on the subject of the infant animal. Prof. R. A. McCance opened the meeting with a general paper on "The Physiology of the Newborn Animal". He began by pointing out what a tremendous physiological upheaval birth must be, and then alluded briefly to the difficulty of finding one's way through the perplexing maze of species and developmental differences to the great general principles of infant physiology. He proposed, nevertheless, to try to do so, and began by saying a few words about the large volume of fluid outside the cells of all newborn animals. There may be some association, he suggested, between this and the anabolic impulse so characteristic of the foetus and newborn. Further expansion of the extracellular fluids by experimental means has in his experience materially reduced the catabolism of tissue protein. He then dealt with the ways and means by which the newborn animal is prepared by Nature to withstand the infections to which it is inevitably exposed the moment it leaves the sheltered world in utero. He traced out the path by which the macromolecules of $\gamma$-globulins and other proteins reach the plasma of the developing organism in the various species, and directed attention to some of the effects of this protein transfer, apart altogether from the establishment of passive immunity. $\mathrm{H}_{\theta}$ spent the rest of his time in discussing aspects of homoostasis. $\mathrm{H}_{\Theta}$ showed, for example, how unstable the body temperature can be in the newborn period, and referred to some of the factors responsible for its maintenance. He took as his examples the poikilothermic newborn rat, the piglet and the human infant, and compared and contrasted them. He then went on to deal with the response to a lack of oxygen, and began by referring to the excellent work which has been done on the subjects of cold and anoxæmia by the great pioneers, such as Harvey, Boyle and particularly Edwards. He made the point that, although there are great species differences, all newborn animals are very tolerant of anoxia. This is due, he believes, to the ability of the newborn animal to utilize anaerobic glycolysis to maintain the structure and function of its essential organs, particularly of its brain. The survival time in nitrogen is largely conditioned by the state of development of this organ, but any study confined to the survival-time tells one nothing about the complex respiratory and cardiovascular changes induced by a lack of oxygen in the first and final days of life. Anaerobic metabolism, he pointed out, utilizes the resources of the body wastefully and leads to the production of potentially dangerous end-products. It also produces less heat. This tends to reduce body temperature, which slows down metabolism all over the body, mitigates to some extent the dangers of the wasteful anaerobic glycolysis, and is an important element in prolonging the lives of anoxic newborn animals, including, in all probability, man. If this is so, resuscitation of the cold blue infant should begin with glucose to provide fuel for glycolysis and oxidation, pass on to re-oxygenation and be followed by warmth only. when oxygenation has become effective.

Prof. McCance then passed on to the subject of food, growth and renal function. This last is generally reckoned to be poor by adult standards in the new. born period, yet the concentration of urea in the serum is normal at birth and remains so. Few have seen the extent or significance of this paradox, but investigations carried out at Cambridge have explained it. The power of growth, it would appear, may be far more important than the operation of the kidney in maintaining the concentration of urea in the body fluids within normal limits. 90 per cent of the protein nitrogen in the diet of a rapidly growing animal may be utilized for the synthesis of tissue protein and only 10 per cent of it appear as urea and other end-products to be excreted by the kidney.

The weakness and helplessness of the infant have been a constant theme with philosophers. Helpless it may be in that it cannot stage its own come-back from an abnormal situation -it has to be brought back. But many of the signs of weakness are really marks of strength, if by strength is meant the ability to survive. The secret of handling and caring for the newborn is to make the most use of the strength with which it has been endowed by Nature, and if its stability has been upset, to restore this physiologically and not in some haphazard way which may seem the obvious one at first sight.

The next two speakers dealt with more specialized branches of the subject. Mr. G. A. Lodge, of the Rowett Research Institute, read a factual paper on 
the nutrition of the young pig. He dealt first with the composition of sow's milk and the quantity secreted at different stages of lactation. The concentration of protein is high in colostrum, associated perhaps with the presence of antibodies; it falls as full milk is established, and thereafter tends to rise, while that of fat and lactose falls. The calciumphosphorus ratio changes from about $1: 2$ in colostrum to $1: 0 \cdot 6$ in normal milk.

A piglet left with the sow takes about $1.5 \mathrm{lb}$. of liquid milk a day during the first week, $2 \cdot 4 \mathrm{lb}$. a day during the third to fifth weeks, then consumption drops to $1.7 \mathrm{lb}$. a day during the eighth week. About $0.8 \mathrm{Ib}$. of dry milk-solids is required to produce each pound of increase in body-weight.

For commercial reasons it is desirable to wean piglets as early as possible, so as to free the sow for the next litter. Weaning at birth has been successful only under laboratory conditions ; and since piglets get all their entibodies through the colostrum, elaborate precautions against infection are necessary if they are to be reared without it. From two days of age piglets can be reared on artificial food. They require liquid food at first, and they are unable to digest starch or sucrose or any protein other than casein for the first week or so. From ten days onwards dry meal diets are generally employed. The optimum amount of fat seems to be about 8 per cent, and of protein 25 per cent, decreasing to 18 per cent after the piglet has reached a weight of $25 \mathrm{lb}$. Piglets ten days old are able to digest starch and all the sugars, though their ability to utilize lactose declines after about three weeks.

'The third paper of the meeting, entitled "The Nutrition of the Early Weaned Calf", was given by Dr. J. H. B. Roy, of the National Institute for Research in Dairying. Dr. Roy explained that by weaning he meant removal of the calf from its mother at an oarly age, rather than changing its diet from liquid to dry food. For centuries the dairy calf has been weaned soon after birth because of the demand for liquid milk for human consumption. The newborn calf, like the adult ruminant, has four stomachs, but only the fourth stomach, or abomasum, is functional, for milk by-passes the rumen and reticulum.

The calf receives all its antibodies through the colostrum. All calves should be given colostrum for the first $24 \mathrm{hr}$., and preferably for four days after birth if deaths from $E$. coli infections are to be prevented. Cortain antibiotics, in particular the tetracyclines, will give protection against these conditions. Calves are normally fed on whole milk for the first three weeks, and thereafter on milk substitutes. Milk substitutes do not give such satisfactory results when fed directly after the colostrum period. The pre-ruminant calf seems to be unable to utilize any carbohydrate other than lactose or glucose, and it cannot tolerate more than $250 \mathrm{gm}$. of sugar a day. Carbohydrates, therefore, cannot provide the main source of energy in milk substitutes during the early post-natal poriod; and moreover, a certain amount of fat seems to be essen. tial for the young calf, and, of the milk by-products, probably only buttermilk contains enough of this. If fat is added to reconstituted dried skimmed milk, it must be properly emulsified and homogenized or it will cause diarrhoea. The digestibility of fat, by piglets, young guinea pigs and pups has been shown to depend upon the chain-length of the constituent fatty acids rather than on their satura- tion. The shorter the chain of saturation the greater the digestibility.

This is probably true for the young calf, although the use of fats containing highly unsaturated fatty acids has also been detrimental to the health of young calves.

No suitable substitute for milk protein in the diet of the pre-ruminant calf has yet been found, and even spray-dried skimmed milk which has been processed with a high pre-heating temperature may be of less value than fresh skimmed milk or milk processed at a lower temperature. This effect may be due to the denaturation of the soluble protein by the heat treatment, or to the fact that such milks do not clot with rennet.

The age at which the ealf turns over to the ruminant method of digestion depends upon the diet which it has received. The longer it has access to a plentiful supply of milk, the less it will want to eat the fibrous and starchy foods necessary for the functional developmont of the rumen. It is a great advantage to the farmer to induce his calf to become a ruminant as early as possible, for once the rumen begins to function cheap foods can be used, and there is no longer the samo risk of diarrhoca. The ingestion of roughage stretches the walls of the reticulo-rumen and increases their capacity. The rumen papilla, however, are stimulated by readily absorbable matcria], not by fibrous foods.

Dr. Roy next turned to the microbial flora of the gut. The abomasum of the young calf supports a large and diverse population of lactobacilli. The typical rumen amylolytic streptococci and protozoa of the adult animal do not become properly established until the rumen $p H$ is stabilized at about neutrality, which does not normally happen until the calf is nearly eight weeks old. The establishment of the rumen microbial flora can be encouraged at an earlier age if the calf can be induced to eat dry food. Grass is by far the cheapest dry food for the young calf, but unfortunately most calves in Britain are born during the winter months when grass is not available in any quantity. With other dry foods most consistently good results have been obtained with weaning at eight weeks, although recently abrupt weaning at three weeks of age has been shown to give satisfactory growth-rates.

In the discussion which followed, Dr. D. P. Cuthbertson asked $\mathrm{Dr}$. Roy whether he believed it better to transfer a calf abruptly or slowly to a ruminant type of diet. Dr. Roy favoured transferring it slowly.

Dr. Magee raised the question of piglet anæmia, which had not been mentioned by Dr. Lodge. A single injection of iron intramuseularly had been found very effective for piglets, and also in certain circumstances for calves. Dr. Roy agreed that if iron is given to calves it raises their hæmoglobin-level, but he pointed out that calves do not generally show clinical signs of anænia as piglets do, presumably because they grow more slowly.

Mr. D'Arcy asked if anyone knew why feeding freshly harvested barley or rye to pigs has such disastrous effects. His own experience covered two prize sows which had had such severe diarrhoea in consequence that they died within two days. Other speakers said that they had heard about this phenornenon, but no one was able to tell the meeting what the toxic factor, if any, could be.

E. M. WIDDowson 